\title{
Tasks of the IPS ,TABOR” in the EU Project MODBRAKE
}

\author{
The paper describes an EU project MODBRAKE concerning standardization ac- \\ tions about high-speed passenger train brakes, also showing the participation of \\ the Institut of Rail Vehicle TABOR in Poznan in the project. A short history of \\ train brakes is presented, discussing briefly the development phases and the \\ benefits of using modules. EU actions concerning standardization actions about \\ railway vehicles, particularly of train brakes under the MODBRAKE program, \\ are presented. The short description of the new brake system with accordance to \\ international TSI standardization is presented.
}

\section{Introduction}

The braking system of a railway train is one of the most important systems in a rail vehicle, ensuring the safety of train traffic and passengers. Depending on their purpose, different kinds of braking modules are used, configured according to criteria of economy, reliability and safety. The modern pneumatic brake stands out in this field; despite some drawbacks it presents undeniable values and ensures a high level of safety, especially in extraordinary situations (e.g. train disruption, disconnection of power and control systems). Presently in high-speed trains they are integrated with other kinds of brake though electronic control elements and signal transmission, which provides higher safety levels compared with the traditional brake system.

\section{Brief history of modular brake systems}

In the past, brake control systems consisted of many single pieces of apparatus in different places, connected directly to the pneumatic system. Access to them and diagnostics of system failures were difficult, increasing the time needed for train repairs and demurrage, which led to higher construction and running costs. Despite their disadvantages, they were utilized because of their simplicity. In the early 20th century, the wider range of tasks that needed to be performed caused complications. Apart from improvements in quality and evolution of brake systems and apparatus, brackets connecting them to the pneumatic installation of the train were introduced, allowing easy removal of the elements of the brake system. This provided better accessibility of the apparatus and reduced the time for which vehicles had to be taken out of operation for brake repairs.
A further development of brake systems was the integration of their elements on the vehicle. The first step involved grouping them in one place, on a socalled brake framework. Brake devices still had their own bracket, but they were grouped in one place on the vehicle, which allowed for better access and relatively easy replacement. Brake systems were still very complex and their production and maintenance very labor-consuming.

The next step, in the second half of the 20th century, was to integrate all, even more complex apparatus, on brake panels. This required manufacturers to prepare many types of apparatus for panel assembly and develop new technologies for pneumatic installation of the boards. They had to ensure reliable and leak proof connections between dozens of the apparatus on the panel.

The example of a brake panel of former design is presented on Fig 1.

Integration of the apparatus and whole braking systems on boards ensured the following:

- Compact construction of the brake control elements and compressed air distribution system thanks to the use of air connections directly to the panel housing, which did not need supports or pipe connections. All pneumatic connections between that apparatus went via the housing of the board; the electrical connections were integrated in a single panel too.

- The ability to radically simplify (compared with the traditional arrangement) the installation of pneumatic brakes.

- The possibility of ergonomic design in the driver's cabin thanks to the small size of the modern brake handle (in comparison with the old pneumatic 

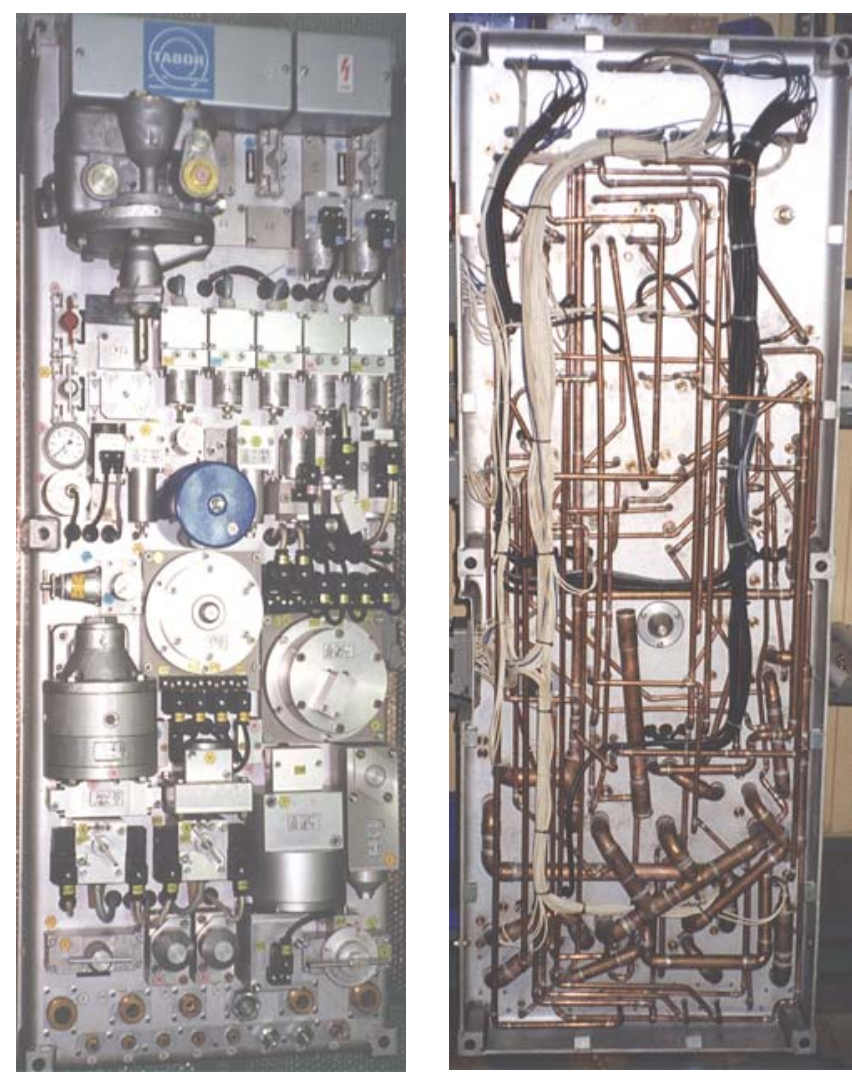

Fig. 1. The brake panel of the former construction [5]

- driver's brake valve) and the smaller number of pipes needed in the cabin.

- The possibility of regulation, checking and acceptance of completed braking and auxiliary systems (combined on the brake panel) outside of the vehicle, followed by easy and fast installation of the ready-made panel in the vehicle.

- Good servicing conditions for the apparatus built into the board thanks to clear structure, good accessibility and easy re- and disassembly

\section{New development of the modular brake systems}

At the end of the 20th century, due to the use of microprocessors in railway brake steering systems, it became possible to simplify the pneumatic and electric brake equipment and to introduce advanced diagnostics and subsequent integration of the system. Global brake manufacturers began production of so-called Modular Brake Systems. An MBS can be installed on the train in a decentralized fashion or integrated on pneumatic panels with easily accessible functional elements and testing points.

The main features of Modular Brake Systems are:

- Compact assembly, consisting of modules that fulfill the requirements of UIC (Union Internationale des Chemins de Fer) and EU standards

- Simple architecture from the user's point of view, thanks to pre-connection of very many elements in compact modules

- Easy plug\&play installation
- Advanced diagnostics (a malfunction is immediately localized and the faulty module can be easily replaced), assuring a high level of safety

- Increased utilization of trains, thanks to the infrequency of failures and very short time necessary for maintenance and repair though replacement of faulty modules

- Significant reduction in electric wiring, thanks to communication via a data bus

- Simplified I/O interface of the modules

- High efficiency and low LCC thanks to the high number of universal elements for different kinds of vehicles

- The ability to adapt to specific user requirements and working conditions

- The ability to add new functions through software updates, without changes in the hardware of the system.

The following brake modules can be distinguished: Brake Command Module placed in the driving car and Local Brake Control Modules situated in each car of the train. The examples of a local brake panel and brake control container are presented in Fig 2 and 3.

The main brake companies have started producing MBS systems. Each of the companies uses their own ideas in terms of division of modules, software, module input and output signals, data transmission systems, measurements, mounting and junctions. These modular braking systems are used in many new trains in Europe (diesel and electric locomotives, traction units etc.). MBS systems are already in use in a few European countries, and their admission for use in most other European countries is either planned or pending.

\section{The MODBRAKE project}

Almost up to the end of the 20th century the European railway market was monopolized by big national railway operators. The UIC was responsible for developing requirements and standards for many kinds of devices (including brakes) for vehicles intended for international traffic. In the field of braking equipment it ensured a high level of safety and interoperability of the European railways.

Recent years have seen privatization in the railway sector, involving the division of national railway operators into many independent private operators. Similarly to other industries, the foundations of a free market in the railway international transport were laid. The EU's goal is to achieve full compatibility of international railway transport in the future, and this has led to the concept of interoperability.

Interoperability of the trans-European railway system means safe and undisrupted railway traffic throughout the whole European Union, ensured by fulfilling cooperatively defined requirements relating 


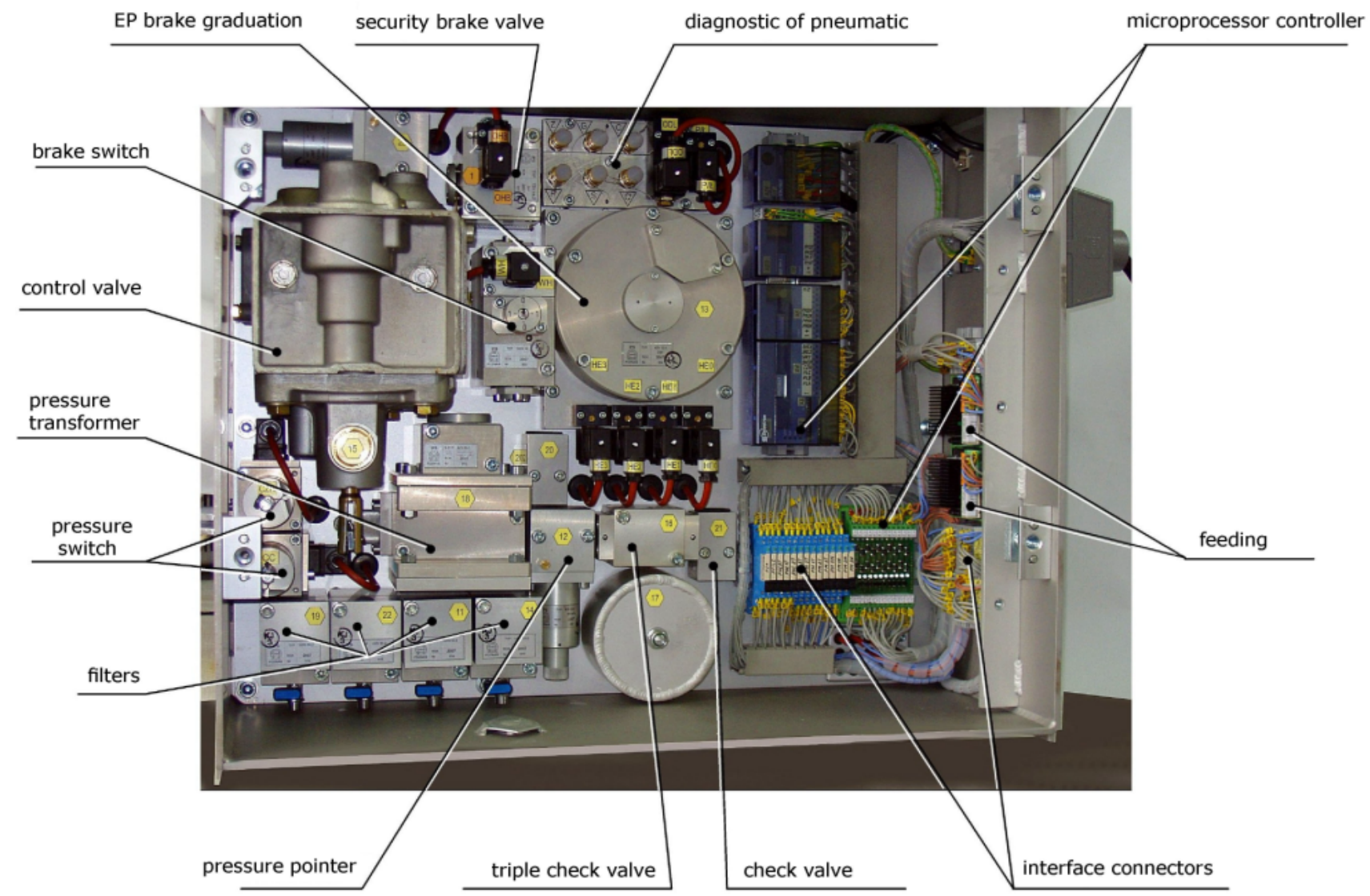

Fig. 2. Local brake control module with microprocessor for EMU (IPS "TABOR”)

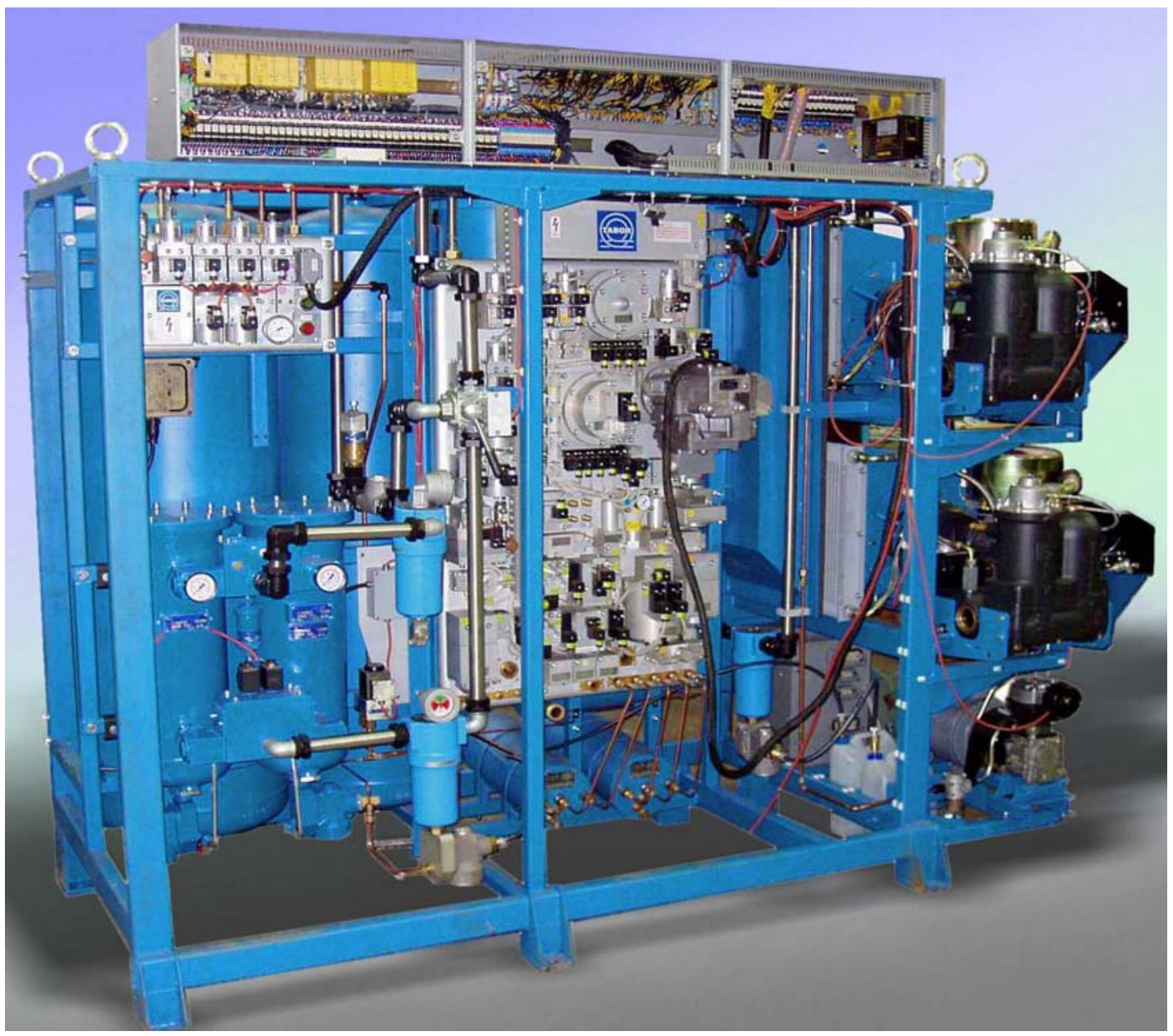

Fig. 3. Locomotive brake container controlled by microprocessors, containing air supply and treatment, brake control module and supplementary pneumatic modules (IPS "TABOR") 
to control, technical and operational conditions.

For these reasons, the directives on conventional trains (2001/16/EC) [1] and for high-speed trains (96/48/EC) [2] were drawn up. Based on those directives, UIC requirements, national and EU requirements - Technical Specifications for Interoperability (TSI) were laid down for conventional and high-speed trains. They define minimal requirements for each system of the train, operation and infrastructure, whose fulfillment will guarantee its compatibility ensuring safe trans-European traffic.

As a result of research and development projects that comply with the above-mentioned technical regulations, there will appear apparatus, installations or modules realizing new complex structures and functions connected with train braking systems. On the other hand there will also be new requirements laid down by railway traffic operators as a consequence of the operation of rolling stock. In order to ensure the interoperability of the new products, structures, functions and requirements should be examined, defined precisely and in the final phase normalized and standardized. Apart from interoperability, this technical harmonization should aim to achieve high safety levels in the operation of European railways.

For this purpose, in the years 2004-2008 the European railway industry launched, as part of the 6th Framework Programme for Research and Technological Development, a jointproject with the name MODTRAIN (modular train) for recently designed high-speed trains with module construction, as shown in [3].

As early as the first phase of realization of the MODTRAIN project it became apparent that the newly-designed modular braking systems for highspeeds are not sufficiently well-defined in European regulations. These complicated systems interact with many other systems in the car, which makes them an important issue to be dealt with. No project of this kind was planned within the large MODTRAIN project. For that reason another independent MODBRAKE project (Innovative Modular Brake Concepts for the Integrated European High Speed Railway System) was investigated in 2006-2009 at the initiative of both train manufacturers and the main European braking system manufacturers. It concerns not only recent brake control modules, but also brake modules on the bogies and the treatment and supply of compressed air.

The braking system is one of the most critical and complex subsystems of rail vehicles; the safety requirements for it are crucial for the train's safety. The present braking system of high speed trains is a connection of various systems, mainly pneumatic and electrical. Electrical (electronic for the most part) systems are involved in the control of the system, while purely pneumatic systems are more widely used for the production of brake forces (bogie brake systems). The variety of systems depends on the supplier. This results in diversity of brake systems' construction principles, design, functional structure, testing, validation and maintenance, and this means increased expense. To reduce this variety and complexity the project proposes modularization of the brake system.

The project is divided into phases.

The first part of the Project was the analysis of the existing standards and regulations, and the elaboration of FRS /SYRS (Functional Requirements Specifications /System Requirements Specifications) for brake modules. Then the modular brake concept was elaborated and evaluated. The internal principles of operation and construction can still be specific to each manufacturer in order to ensure future technological progress based on competition.

In order to demonstrate the level of compatibility of the interfaces the first sample prototypes following the ideas of modular brake constructions were built. The next goal was to create a method of common validation tests and carrying out the tests on the prototypes.

The, proposed within a framework of the Project, brake system for high speed trains is an electropneumatic system with modern electric control utilizing numeric control based on microprocessors, where a brake force system is executed in pneumatic. The main groups of the brake system were researched, in particular:
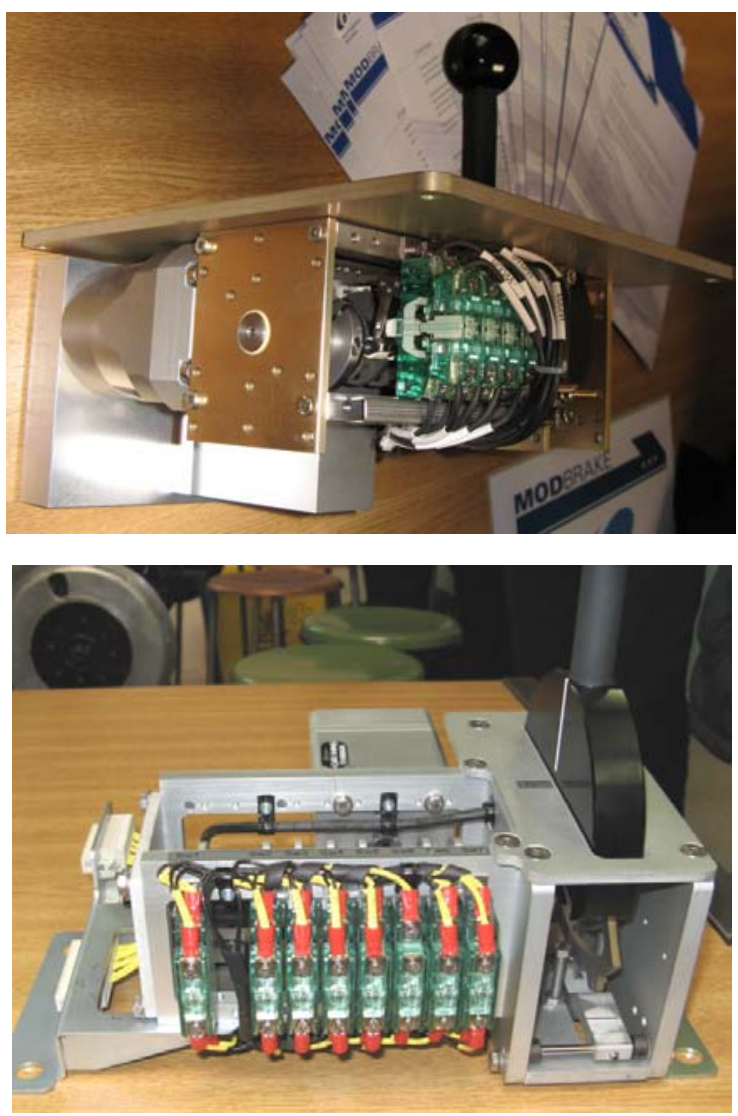

Fig.4. Prototype manipulators of Knorr (left) and of Faiveley (right) [5] 
- Air supply,

- Brake control, including brake control handle, brake valves and devices (fig. 4),

- Bogie brake equipment, including all mechanical elements of the disc brake (fig. 5 and 6).

During the Project investigations some types of the high speed train brake control were proposed. One of them is the TSI compliant brake system in which the control through the train is only electric, consisting of the main line and a safety loop. The pneumatic brake pipe is unnecessary. Brake signals are digital coded via e.g. CAN, Ethernet bus. The brake signal is received trough local brake unit placed in every car, then it is transmitted to pneumatic pressure and acts on mechanical friction brake. The system standardised in the project has developed functions of reliability and safety. Quality of the electric signal and of the electric and pneumatic supply is being checked during its work. Except for the main electric bus, the system has independent electric safety loop line (fulfilling the security role of the former brake pipe) connecting all the cars of the train and returning to the automatic brake controller. Any disruption of the line would cause the safety braking of the train. The main control line is redundant, as it fulfils described earlier security function, checked by hardware and software.

Electric local brake control of each car (Fig. 5) is controlled with both the signals of the main brake line and the safety loop.
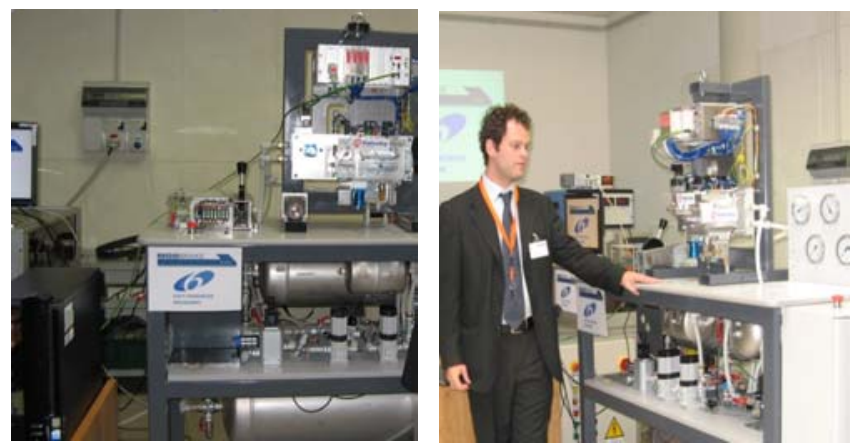

Fig. 5 Test stand of the local brake modul with brake controller placed in Politecnica di Torino presented by author of the investigations [5]

The safety loop is secured from: decay or surplus of the feeding, short circuit or breakdown. Each local brake control is supervised by the watch dog, which generally can protect against errors or false commands in software.

The high speed train (including described above electric brake control system) can be connected with another train that does not have electric brake control. In this case in the high speed train the brake pipe will be activated and the control signal will be distributed in both fashions. In this setting, in case of an emergency the train brake would be controlled pneumatically and thus fulfill the basic requirements of the UIC Cards.
Reassuming: the malfunctioning of that system will cause in justified situations emergency braking of the whole train. The system possesses required redundancy, assuring braking safety not smaller than that of a classic pneumatic brake, while the new electric control has some advantages impossible to achieve with purely pneumatic systems.

The modules performing brake forces (brake calipers and brake discs) were the last investigated subsystems of brake. Fig. 6 presents elaborated and executed in the Project brake modules in presentational form. They were designed according to requirements elaborated in the described Project, which will be in the nearest future the basis of new European norms.

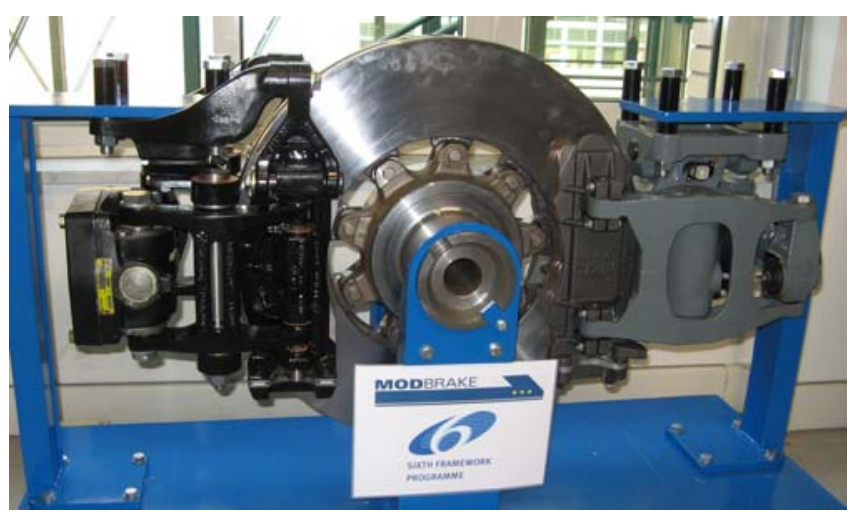

Fig. 6. Caliper prototypes of Faiveley (left) and Knorr (right) assembled for presentation to one disc [5]

\section{The goals reached in the MODBRAKE Projekt}

- Harmonising operators' requirements for subfunctions beyond the existing TSI, EN and UIC norms.

- Standardising brake system module interfaces, currently depending on brake manufacturers' individual design. This includes interfaces with Train Control Monitoring System (TCMS) and other sub-systems of the rolling stock, mainly for highspeed trains and particular traction units.

- Enabling modular design of brake modules independently of some crucial modules/components maintained independently from the supplier (interchangeability of main modules, also life-cycle cost reduction).

- Harmonising test, validation, assessment and maintenance procedures to enable mutual recognition at European level.

- Creating a new culture of cooperation between the industry and operators for a new generation of rolling stock.

- Delivering the results with clear benefits for all concerned: the industry, operators and customers.

- A major contribution to forming a structured modular approach for design and manufacture of future rolling stock based on a common European approach. 


\section{Participation of the IPS TABOR in works of the MODBRAKE Project}

One of the research centers participating in MODBRAKE was the Rail Vehicles Institute TABOR of Poznań, Poland. It participated in various tasks of the Project:

- presented the legal, technical and operating issues concerning train brakes in Poland,

- participated in functional and system analysis of brake systems

- participated in the MODBRAKE brake module research programs, especially:

- evaluated the model prototypes' compliance with the requirements of ORS 612 (actual renamed to UIC 612 Karte),

- participated in testing and independent assessment of the brake controllers produced by another participants of the Project (Fig. 4)

- in collaboration with the Turin University of Technology prepared standardized programs of selected functional modules located on the bogie (Fig.5),

- performed the test of calipers constructed and produced by other participants of the MODBRAKE Project; they were delivered to IPS TABOR and investigated on his own stands.

The mentioned extensive investigation of the calipers had various goals:

- accordance of the construction with the requirements included in MODBRAKE documents

- tests of caliper operation in comparison with MODBRAKE requirements

- tests of the temporary and fatigue endurance of the whole caliper and of its selected elements and comparing with results of FEM method (Fig. 10)

- verification of caliper operation in winter; tests performed in low temperature (up to $-40^{\circ} \mathrm{C}$ ) in climate camera including tests with intense icing (Fig. 11).

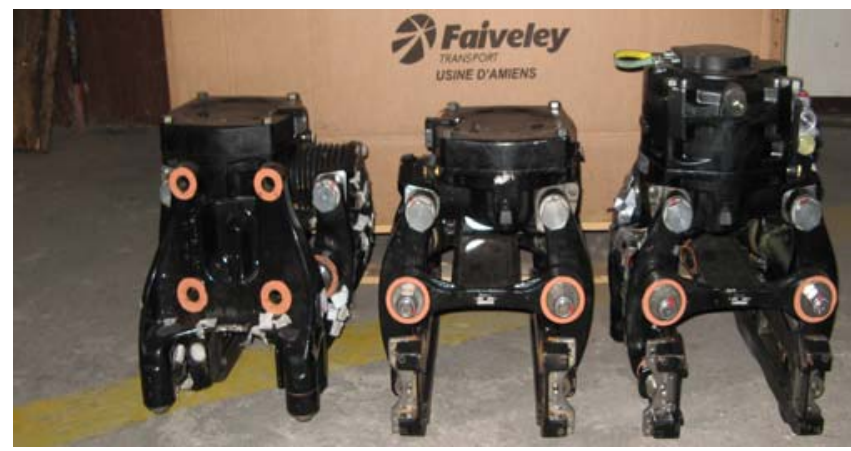

Fig. 7. Calipers supplied to tests [5]

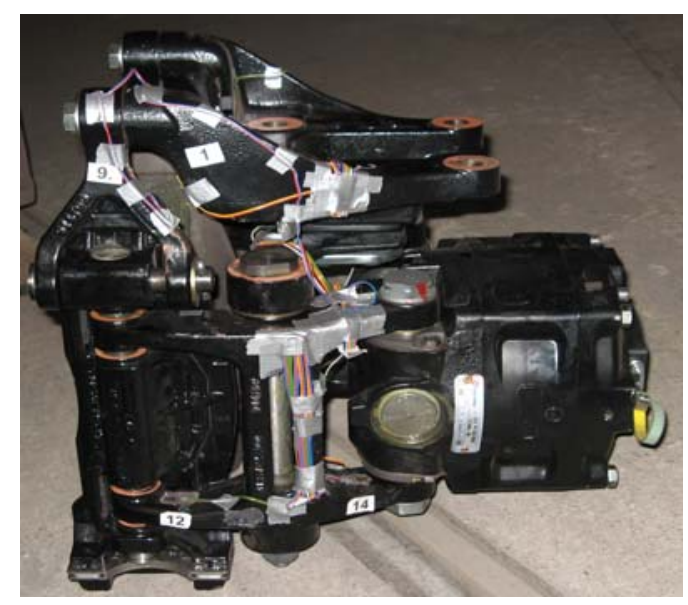

Fig. 8. Caliper prepared to endurance tests [5]
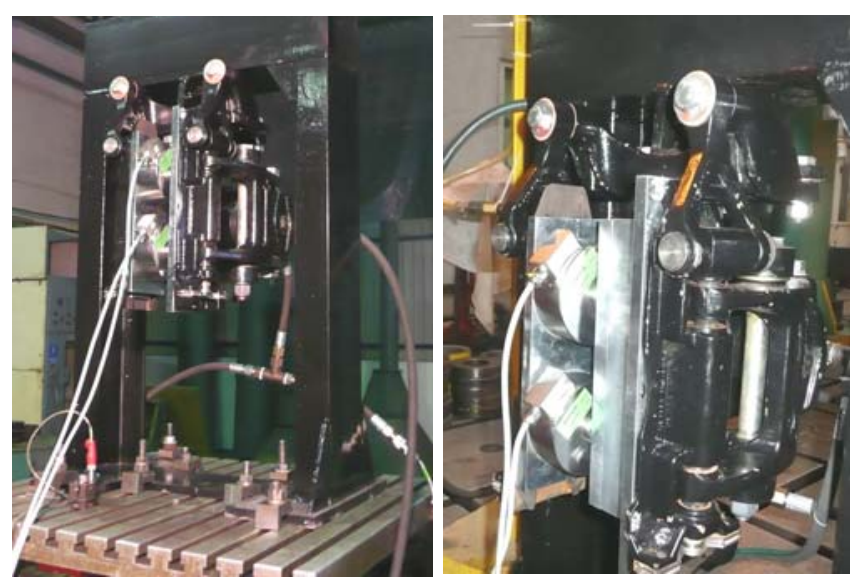

Fig. 9. Caliper on the shaker and during its efficiency tests [5]

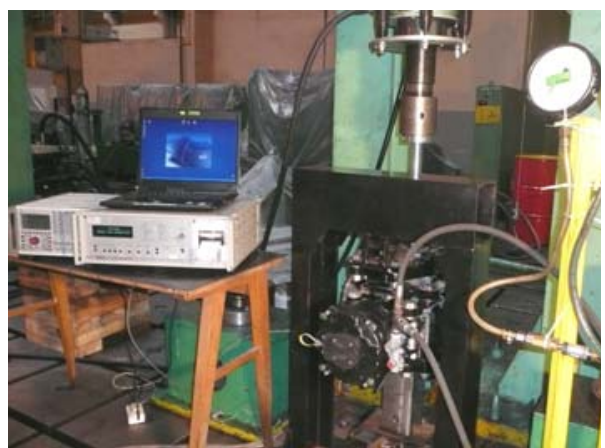

Fig. 10. Caliper during the fatigue strength tests [5]

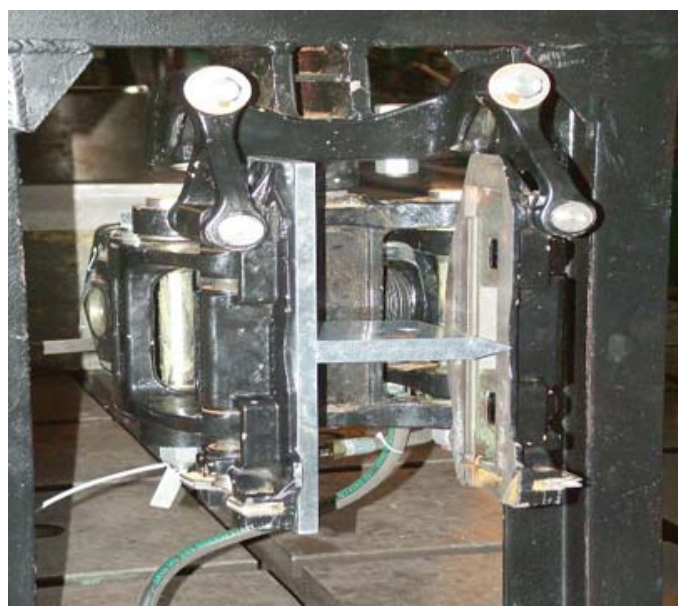

Fig. 11. Caliper during the brake holder stiffness tests [5] 

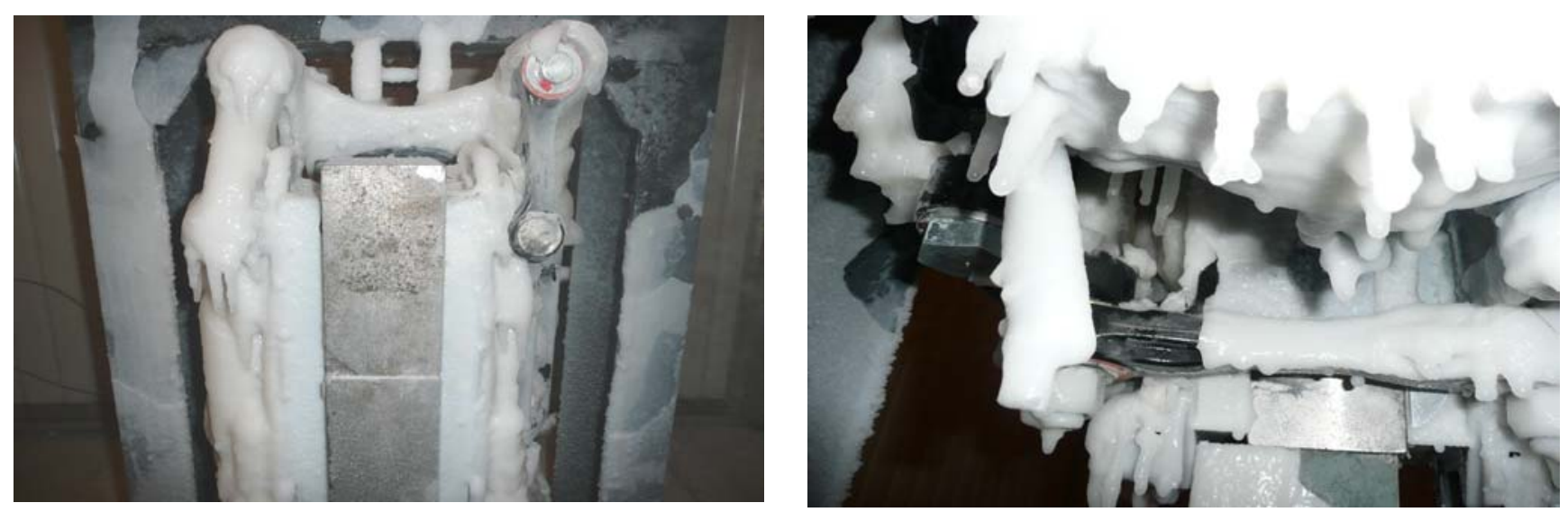

Fig. 12. Caliper during tests in iced conditions in the temperature of $-40^{\circ} \mathrm{C}$ [5]

The tests confirmed accordance of the calipers tested in the Project with proposed European norms, contributing to the objectives of MODBRAKE which will enable design engineers to dimension components more precisely.

All this will lead to further standardisation of railway brake specifications and eventually improving its interoperability.

\section{Conclusion}

The activities in Project MODBRAKE were performed as a form of cooperation of various producers, railway distributors and scientific institutions and were concentrated on the development of new brake systems for high speed passenger trains and its future standardization, necessary to ensure interoperability and competition possibilities of the European Union railway transport. The new system will have very extended, comparing with present ones, electric control. It will increase safety, reliability and diagnose possibilities of the brake system. The braking forces will be executed pneumatically.
The IPS TABOR participated in the development of the future brake systems and in the modification of the present rail stock along with future development tendencies or standards.

\section{Bibliography:}

[1] Council Directive 2001/16/EC of 19 March 2001 on the interoperability of the conventional rail system.

[2] Council Directive 96/48/EC of 23 July 1996 on the interoperability of the trans-European high-speed rail system.

[3] Durzyński Z.: Pojazdy z systemami modułowymi sposobem na zwiększenie konkurencyjności kolei. Konferencja QSEV 2007

[4] Kaluba M., Piechowiak T. The european union modbrake program - interoperability and safety of railway braking systems. Konferencja QSEV 2009. Kraków

[5] Photographs made by the team during the MODBRAKE project and from IPS "TABOR", Poznań.

[6] Driver Machine Interfaces for Traction Units and Driving coaches. ORS 612-0. 